underemployment constituting its dominant features. Instead, Lange restated that a socialist economy is a better institutional framework for economic theory itself $(1942,1944)$. He also reaffirmed the social relevance of economics (in opposition to the supporters of the "compensation principle") through an important article on welfare economics (1942).

Ultimately the two fields of research merged into an attempt at rewriting a more "generalized" economic theory (1945), not reliant on the tacit assumption of a capitalist system, but compatible with different institutional contexts, first and foremost that of a socialist society.

The analysis of these periods of Lange's evolutionary thinking led the author to conclude that the young Oskar Lange was indeed a key figure in the debates of the 1930s and 1940s, and his works were connected in a wider scientific project aimed at conjugating the higher discipline of scientific rigor with the maximum degree of social relevance. For this purpose, the Polish economist made a distinction between the "pure abstract" and the "effective" level of investigation. With the former, he generally accepted traditional theory, albeit with several qualifications and updates. With the latter, he explored many implications of Schumpeterian and Keynesian theories, though radicalizing them (in terms of policy).

His entire body of literature from this period has, therefore, been interpreted as a fresh attempt to critique mainstream theory "from the inside," motivated by its lack of realism.

\title{
THE CARDINALIST MANIFESTO: THE EPISTEMOLOGY OF THE MEASURABILITY OF UTILITY
}

\section{JONATHAN ANDREAS*}

\author{
Primary Supervisor: Joseph Persky \\ Department, Section or School: Economics Department \\ University: University of Illinois at Chicago \\ Date of Convocation: May 9, 2010 \\ Language of Thesis: English
}

Over the past century, economists have increasingly relied upon utility theory to the point that some economists have redefined the discipline as "the application of the principle of utility to every aspect of human behavior" (Prieto 2008, p. 338). Economics made its big shift onto a foundation of utility theory during the ordinal

\footnotetext{
*Assistant Professor of Economics at Bluffton University, Bluffton, $\mathrm{OH}$.
} 
revolution, and it came about because the ordinalists rehabilitated the utility theory of the nineteenth-century marginal revolution, and made utility seem more scientific. The ordinalists promoted this branch of economic theory and Hicks coined the term "marginal revolution" in his efforts to promote it (1935, p. 2). Previously, historians have paid little attention to how the ordinal revolution reshaped economics. Instead, they have focused on earlier periods in utility theory before it became central to economics. Historians usually only briefly mention the ordinal revolution as the inevitable conclusion to the history of the marginal revolution, but this is Whiggish history. Contrary to the standard historiography of utility, the ordinal revolution was not a bloodless coup that ended in the early 1930s. There was a vigorous debate in the literature that peaked much later, in the early 1950s. The debate was resolved by the end of the 1950s, and henceforth ordinalism has become so dominant that even the term "cardinal utility" has been disappearing from use in the economics literature on Jstor. And when the term is used, it is often accompanied with disparagement or apology. Textbooks confirm this orthodoxy. Almost all textbooks surveyed unambiguously state that utility is ordinal.

The ordinal revolution created a unique and flawed theory of measurement. It is manifest to measurement theorists that nearly all the utility functions that economists call 'ordinal' are actually cardinal. Indeed, the most fundamental ordinalist concept, the marginal rate of substitution (MRS), uses cardinal utility. Ironically, the MRS is the very concept that every textbook uses to explain that utility is ordinal, and yet the MRS not only uses cardinal utility, but it is more strongly cardinal than even the interval scale used by von Neumann and Morgenstern's expected utility. The MRS assumes that utility has a ratio scale because it is a ratio of two utility measures. The issue is clear when illustrated using temperature measurements. It is meaningless to take a ratio of interval-scale measurements like temperature in Fahrenheit. Twenty degrees Fahrenheit is not double ten degrees Fahrenheit. It was impossible to make a meaningful ratio of temperatures until scientists developed a ratio-scale measurement: twenty degrees Kelvin is double ten degrees Kelvin. Ordinal measures are even more mathematically limited than interval-scale measures, and so it is impossible to do basic mathematical operations with them, like taking derivatives or adding two values of utility together. When economists do these sorts of routine mathematical manipulation of utility functions, they are necessarily predicated on cardinal utility.

All the other ordinalist epistemological arguments were also flawed. The Occam's razor argument for dismissing cardinal utility was a logical fallacy. Ordinalism is not inherently less introspective, and it is debatable whether reducing introspective evidence is desirable for a subjective phenomenon like utility. Ordinalism is more "general" in the way that mathematicians (and mathematical economists) use the word, but this is only a virtue for mathematical purposes. In other disciplines, "generality" is a liability, and so too here: generality makes ordinalism vague and untestable. Ordinalism does not by itself eliminate controversial welfare applications. Only eliminating interpersonal comparability does that, so this ordinalist misgiving about cardinalism was misplaced. These two concepts are often conflated, but it is crucial to distinguish between them because although what economists call 'ordinal utility' is really cardinal, it does not use interpersonal comparability, without which it is useless for welfare economics. Although Robbins is commonly considered to have 
been an ordinalist leader, he was actually a cardinalist who strongly objected to interpersonal comparisons of utility for welfare.

Despite flawed reasoning, the ordinalists won their debate due to sociological reasons and historical accidents: they were at the right place at the right time. But times have changed and the ordinal revolution could not happen today for the same reasons that will be its undoing. Despite this, the Cardinalist Manifesto does not call for a cardinalist counter-revolution. There is no need to change anything in positive utility theory except our interpretation of it. Economists must simply accept that measurement theory shows that our existing economic models cannot work unless each person can perceive her own cardinal utility, and we can continue to use them just as before. Just as the ordinal revolution allowed economists to continue using nearly all the same positive models of utility as before, all existing models of utility will continue to be used. The only significant economic theories that the ordinalists successfully eliminated were some cardinal welfare theories. ${ }^{1}$ The ordinalists successfully reformulated theoretical welfare economics, but by doing so they made welfare theory impractical for policy applications. This created a split between theoretical and applied welfare economics. Applied welfare has quietly continued to use cardinal "money-metric utility" with the tacit approval of ordinalism.

Ironically, the Cardinalist Manifesto demands that welfare economics should become more ordinalist in accordance with measurement theory. Applied welfare economics should focus on median income, which is an ordinal statistic, rather than the most common applied welfare statistics: per capita GDP or GDP growth. These are cardinal representations of welfare, and median income is a readily available ordinal replacement that should be used whenever welfare evaluations are made. GDP is an appropriate statistic for evaluating productivity (which is arguably cardinal), but not for welfare (which is ordinal). Welfare is better measured using ordinal median income rather than using the cardinal money-metric utility underlying per capita GDP.

\section{REFERENCES}

Hicks, John R. 1935. “A Suggestion for Simplifying the Theory of Money.” Economica 2(5): 1-19.

Prieto, Jimena Hurtado. 2008. "Jeremy Bentham and Gary Becker: Utilitarianism and Economic Imperialism." Journal of the History of Economic Thought 30(03): 335-357.

\footnotetext{
${ }^{1}$ They rejected the Pareto definition of complements and diminishing marginal utility, but the latter soon snuck back into economic analysis for many positive applications, and it remains discouraged only for welfare applications.
} 